\title{
Image enhancement for digital radiography
}

Digital imaging systems for plain radiography

Springer; 2013. p. 109-136. DOI: 10.1007/978-1-4614-5067-2_8

Luís Lança and Augusto Silva

\section{Abstract}

Once in a digital form, a radiographic image may be processed in several ways in order to turn the visualization an act of improved diagnostic value. Practitioners should be aware that, depending on each clinical context, digital image processing techniques are available to help to unveil visual information that is, in fact, carried by the bare digital radiograph and may be otherwise neglected. The range of visual enhancement procedures includes simple techniques that deal with the usual brightness and contrast manipulation up to much more elaborate multi-scale processing that provides customized control over the emphasis given to the relevant finer anatomical details.

This chapter is intended to give the reader a practical understanding of image enhancement techniques that might be helpful to improve the visual quality of the digital radiographs and thus to contribute to a more reliable and assertive reporting.

Keywords: Radiography; Image enhancement; Diagnostic value; Digital image processing; Digital radiograph; Visual enhancement; Brightness; Contrast; Anatomical details; Reporting; Reliability. 